The Commonwealth Fund, among the first private foundations started by a woman philanthropist-Anna M. Harkness-was established in 1918 with the broad charge to enhance the common good.

The mission of The Commonwealth Fund is to promote a high performing health care system that achieves better access, improved quality, and greater efficiency, particularly for society's most vulnerable, including low-income people, the uninsured, minority Americans, young children, and elderly adults.

The Fund carries out this mandate by supporting independent research on health care issues and making grants to improve health care practice and policy. An international program in health policy is designed to stimulate innovative policies and practices in the United States and other industrialized countries. 
The

COMMONWEALTH

FUND

\title{
CREATING CONNECTIONS: AN EARLY LOOK AT THE INTEGRATION OF BEHAVIORAL HEALTH AND PRIMARY CARE IN ACCOUNTABLE CARE ORGANIZATIONS
}

\author{
Katherine I. Tierney, Aleen L. Saunders, and Valerie A. Lewis
}

\section{DECEMBER 2014}

\section{ABSTRACT}

Despite the potential benefits of models that integrate behavioral health and primary care, fiscal, structural, and cultural barriers prevent organizations from pursuing them. Accountable care organizations (ACOs) may be better positioned to implement integrated care because of modified reimbursement structures with an emphasis on care coordination. This report showcases integration approaches at two ACOs. The first uses a colocation plus collaboration model that improves connectivity between providers through proximity and improved sharing of information. The second uses a model that adds behavioral health specialists to the primary care team to bolster the capacity of PCPs in managing mental health and substance abuse conditions. We identify two factors that enable successful implementation: participation in an ACO and selection of an appropriate model of integration. External partners can support the spread of integrated models of care through education and collaborative learning. 



\section{CONTENTS}

About the Authors $\quad 6$

$\begin{array}{ll}\text { Executive Summary } & 7\end{array}$

$\begin{array}{ll}\text { Introduction } & 8\end{array}$

$\begin{array}{ll}\text { About This Study } & 8\end{array}$

Findings 9

Crystal Run Healthcare ACO 9

Essentia Health ACO 11

$\begin{array}{ll}\text { Conclusion } & 14\end{array}$

$\begin{array}{ll}\text { Notes } & 16\end{array}$

\section{LIST OF EXHIBITS}

Exhibit 1 Crystal Run Healthcare ACO and Essentia Health ACO: Organizational Comparison

Exhibit 2 Behavioral Health Characteristics and Capabilities of Crystal Run Healthcare ACO and Essentia Health ACO

Exhibit 3 Roles and Responsibilities of Crystal Run Healthcare ACO Behavioral Health Providers

Exhibit 4 Roles and Responsibilities of Essentia Health ACO Behavioral Health Providers

Appendix Behavioral Health and Primary Care Integration Spectrum 


\section{ABOUT THE AUTHORS}

Katherine I. Tierney is a health policy fellow at The Dartmouth Institute for Health Policy and Clinical Practice. Her research examines the formation and development of accountable care organizations and the impact they may have on vulnerable populations and the safety net. Ms. Tierney previously worked with individuals with severe and persistent mental illness as case manager at a community mental health center in New Hampshire.

Aleen L. Saunders, M.I.A., is a research project director at The Dartmouth Institute for Health Policy and Clinical Practice. Her recent research uses qualitative methods to evaluate health care delivery and payment reforms, specifically accountable care organizations and accountable health communities. Previously she worked in nonprofit and consulting settings, leading program evaluations assessing the impact of health interventions in the United States and internationally. Aleen holds a master's degree from Columbia University.

Valerie A. Lewis, Ph.D., is assistant professor at The Dartmouth Institute for Health Policy and Clinical Practice. Dr. Lewis's work focuses on delivery and payment reform, and she leads the institute's research on the effect of payment reform on vulnerable populations and the safety net. She received her M.A. and Ph.D. in sociology and demography from Princeton University. Previously, Dr. Lewis was the Legatum Post-Doctoral Research Fellow at Harvard University's John F. Kennedy School of Government.

Editorial support was provided by Deborah Lorber. 


\section{EXECUTIVE SUMMARY}

Individuals with mental illness are among the highestneed, costliest patients in the U.S. health care system, yet they receive inadequate behavioral health care. Researchers have proposed various models that integrate behavioral health with primary care. These approaches have the capacity to improve patient care and outcomes in terms of both physical and behavioral health. However, implementing integration models under traditional fee-for-service payment structures presents significant challenges. Emerging payment models-like accountable care organizations (ACOs) may allow for more coordinated care, including integrated behavioral and physical health care. ACOs are groups of providers held accountable for the quality and total cost of care of a defined patient population. Under the model, groups of providers receive modified reimbursements that offer incentives to reduce costs and improve care.

This report explores how ACOs are approaching the integration of behavioral health into primary care by showcasing two models of behavioral health and primary care integration. The two ACOs vary in their approach to integration as well as in other characteristics. The first, Crystal Run Healthcare ACO, is using a combination of integration approaches, which we refer to as a colocation plus collaboration model. The goal is to improve collaboration among providers through proximity and improved information sharing. While the roles of the behavioral health and primary care providers remain relatively traditional, colocation within the same building creates an opportunity for improved care transitions and communication between providers. This $\mathrm{ACO}$ also is using information technology systems to enable better communication and foster knowledge sharing between behavioral health specialists and primary care providers (PCPs).

The second ACO, Essentia Health, has developed an integrated model that embeds several behavioral health specialists within primary care teams, colocates providers, and establishes structures for frequent communication and close collaboration in patient care. This model is often referred to as a primary care behavioral health model. The behavioral health providers' roles are adapted to support the primary care physician, and the primary care physician retains supervision of the patient's psychiatric care. The goal is to build the capacity of PCPs to treat behavioral health patients and reduce the need for referrals to behavioral health specialists.

Both ACOs stated that early, informal feedback on their programs was overwhelmingly positive. More data will be needed to evaluate the effectiveness of integrated care for patient outcomes and the factors that lead to long-term, successful integration. However, from these case-studies two factors arise as vital to the successful implementation of integrated care models: 1) participation in a nontraditional payment system, such as an ACO, and 2) informed selection of an appropriate model of integration. Additionally, these case studies suggest the important roles of payers, states, or learning collaboratives in increasing the use of integrated care models. These partners are ideally situated to provide educational opportunities to ACOs considering or pursuing integrated care. The success and widerange adoption of these models will rely on those ACOs and their partners at the forefront of care delivery transformation to adopt, test, and refine the models. 


\section{CREATING CONNECTIONS: AN EARLY LOOK AT THE INTEGRATION OF BEHAVIORAL HEALTH AND PRIMARY CARE IN ACCOUNTABLE CARE ORGANIZATIONS}

\section{INTRODUCTION}

Individuals with mental illness are among the highestneed, costliest patients in the U.S. health care system, yet they receive inadequate care from the behavioral health system. ${ }^{1}$ While many factors contribute to the shortcomings of the behavioral health care system, fragmentation between behavioral and physical health providers is a central issue. ${ }^{2}$ As a result of this fragmentation, patients receive uncoordinated care. They may receive duplicated services or they may not get appropriate care, both of which result in worse quality care. Researchers have proposed various models that integrate behavioral health and primary care, which may improve care and outcomes in terms of both physical and behavioral health. ${ }^{3}$ Models range from those that focus on improving communications to others that seek to create a fully merged behavioral and physical health team. ${ }^{4}$ Implementing integration models under traditional fee-for-service payment structures presents significant challenges. For example, services that are essential to integrated behavioral health care models, such as case consultations and same-day physical and mental health appointments, are not consistently billable under fee-for-service arrangements. ${ }^{5}$ Consequently, these models are not widely implemented, despite their promise. ${ }^{6}$

Emerging payments models-like accountable care organizations (ACOs) - may allow for more coordinated care, including integrated behavioral and physical health care. ${ }^{7}$ ACOs are groups of providers held accountable for the quality and total cost of care of a defined patient population, ${ }^{8}$ and receive modified reimbursements (e.g., shared savings) that provide financial rewards to reduce costs and improve quality. ${ }^{9}$ These modified incentive structures give providers more flexibility to use services not traditionally reimbursed, such as care management programs, health coaching, or following up with patients by phone or email. In addition, ACOs are encouraged to focus efforts on high-need, high-cost patients, like people with mental health or substance abuse diagnoses. ${ }^{10}$ Thus, ACOs may be well positioned to implement integrated behavioral health and physical health care. ${ }^{11}$

There has been little research documenting how ACOs are approaching the integration of behavioral health into primary care or measuring how frequently these models are used or adopted in ACOs. However, recent evidence suggests that integrated care models are relatively rare in ACOs. ${ }^{12}$ In this report, we showcase two innovative models of behavioral health and primary care integration. Because of the emergent nature of this field, additional data on cost, quality, patient experience and outcomes is not yet available. Thus, this piece is not intended to evaluate the efficacy of the models nor to describe the entire range of integration models available, but rather to illustrate the current implementation of two unique approaches. The first organization, Crystal Run Healthcare, recently began using colocationbehavioral health providers are located within the same building as primary care providers. Additionally, this ACO is seeking to improve collaboration among behavioral health providers and other providers throughout the ACO. We refer to this combination of models as a colocation plus collaboration model. The second organization, Essentia Health, has a more deeply integrated model that embeds behavioral health providers directly into the primary care team, a model called primary care behavioral health.

\section{ABOUT THIS STUDY}

We selected ACOs that were implementing an integrated behavioral health and primary care program. Further, we aimed to select two sites that would include a spectrum of integration and ACO characteristics, such as composition, types of contracts, number of attributed patients (see Appendix for more on the integration spectrum).We conducted semistructured, in-depth onehour phone interviews with clinical leaders (including 
chief medical officers and directors of specialties such as mental health services and primary care services) at Crystal Run Healthcare and Essentia Health (Exhibit 1). Each ACO was interviewed twice, in August 2013 and in January 2014. The first interview focused on broad behavioral health topics, including type of behavioral health providers and services in the ACO, the integration of behavioral health with medical care, and challenges around behavioral health. A second followup interview focused on specific information about the integration models, including provider responsibilities, changes in clinical operations and work flow, and model-specific challenges and benefits. Interviews were recorded, transcribed, and analyzed. In addition to the interview data collected, we referenced materials describing the structure and roles of the practitioners provided by Essentia Health ACO in our analysis.

\section{FINDINGS}

Two ACOs, Crystal Run Healthcare ACO and Essentia Health ACO, sit at different points along the integration spectrum and demonstrate the diversity of ways ACOs might integrate primary and behavioral health care. Their models, which have been designed and tailored by each site, are described in-depth in this section and compared in Exhibits 1 and 2.

\section{Crystal Run Healthcare ACO}

Crystal Run Healthcare ACO serves the lower Hudson River Valley and Catskills region of New York State. It is composed of a multispecialty group with 16 clinics and 300 providers. The ACO's Medicare Shared Savings Program contract began in April 2012, with no additional $\mathrm{ACO}$ contracts at the time of our interviews. Approximately 10,800 patients are attributed to the ACO through the Medicare contract. Crystal Run Healthcare decided to integrate behavioral health in large part because of its participation in the ACO contract with Medicare. The organization hopes that providing behavioral health internally will improve patients' access to behavioral health care and the quality of care delivered.

\section{Integration Approach}

Crystal Run Healthcare is using a colocation plus collaboration model. It also is supporting integration in two additional ways: using information technology systems that enable better communication and fostering opportunities for knowledge sharing between behavioral health and primary care providers. The goal is to improve collaboration among providers through proximity and improved sharing of information. Ultimately, the organization hopes this approach will reduce costs in expensive areas, such as hospital admissions.

\section{EXHIBIT 1. CRYSTAL RUN HEALTHCARE ACO AND ESSENTIA HEALTH ACO: ORGANIZATIONAL COMPARISON}

\begin{tabular}{|c|c|c|}
\hline & Crystal Run Healthcare ACO & Essentia Health ACO \\
\hline Location(s) & New York & Wisconsin, Minnesota, North Dakota, Idaho \\
\hline \multirow{2}{*}{$\begin{array}{l}\text { ACO contracts, start date, } \\
\text { risk type }\end{array}$} & & $\begin{array}{l}\text { Minnesota Health Care Delivery Systems } \\
\text { Demonstration (Medicaid ACO), January 2012, } \\
\text { two-sided risk beginning in second year }\end{array}$ \\
\hline & & $\begin{array}{l}\text { Private payer ACO contracts, several contracts } \\
\text { with various risk levels and start dates }\end{array}$ \\
\hline
\end{tabular}

Source: Authors' analysis. 


\begin{tabular}{lcc}
\hline & Crystal Run Healthcare ACO & Essentia Health ACO \\
\hline $\begin{array}{l}\text { Number of full-time equivalent behavioral health } \\
\text { providers in the integrated program }\end{array}$ & 2 & $\begin{array}{c}12 \\
\text { (2 providers slated for hire) }\end{array}$ \\
\hline $\begin{array}{l}\text { Specialists throughout the ACO } \\
\text { Prescribing behavioral health specialists }\end{array}$ & Yes & Yes \\
Substance abuse specialists & No & Yes \\
Behavioral health paraprofessionals & No & Yes \\
\hline Services, treatments, and facilities throughout the ACO & & \\
Behavioral health screenings & Yes & Yes \\
Psychiatric hospital treatment & No & Yes \\
Outpatient treatment & Yes & No \\
Specialized detoxification facilities & No & Yes \\
Outpatient substance abuse treatment & No & Yes \\
\hline
\end{tabular}

Source: Authors' analysis.

To initiate its integration model, the ACO

hired two new full-time psychiatrists and plans to bring on several social workers. ${ }^{13}$ These providers function in traditional behavioral health roles (Exhibit 3).

While the psychiatrists provide specialized behavioral health care, primary care providers are responsible for carrying out depression screening and providing referrals as appropriate. The psychiatrist and primary care provider roles are similar to those in nonintegrated care models, but the interaction between providers is different. The psychiatrists work in the same building as the ACO's largest primary care practice, and the use of shared space increases contact and allows for collaborative care. For example, PCPs can interact with and obtain informal consultations or treatment suggestions from the behavioral health specialists. In addition, colocation has increased the possibility for improved care transitions-like a warm hand-off, where a PCP introduces the behavioral health provider to the patient. Because the psychiatrists are often booked out for several weeks, warm hand-offs and sameday appointments are still somewhat limited. As a result of limitations of behavioral health staffing, patients with acute needs, such as severe psychosis, are still referred to facilities external to the ACO.

\section{Crystal Run Healthcare ACO is also leverag-} ing existing information technology systems to further support communication and collaboration for colocated and noncolocated sites. All the providers within the ACO are connected through a shared electronic medical record. One important feature is the ability of

\section{EXHIBIT 3. ROLES AND RESPONSIBILITIES OF CRYSTAL RUN HEALTHCARE ACO BEHAVIORAL HEALTH PROVIDERS}

\begin{tabular}{|c|c|c|c|}
\hline $\begin{array}{l}\text { Provider title (location, } \\
\text { full-time/part-time) }\end{array}$ & Responsibilities & Direct patient care role & Availability to PCPs \\
\hline \multirow[t]{2}{*}{$\begin{array}{l}\text { Psychiatrist } \\
\text { (on-site, full-time) }\end{array}$} & $\begin{array}{l}\text { Provides and manages psychiatric } \\
\text { care, including making psychiatric } \\
\text { diagnoses, prescribing and managing } \\
\text { medications, and developing } \\
\text { psychiatric treatment plans. }\end{array}$ & $\begin{array}{l}\text { Comprehensive-Responsible } \\
\text { for managing psychiatric care. }\end{array}$ & $\begin{array}{l}\text { Limited-Available as } \\
\text { their schedule allows } \\
\text { for consultation, warm } \\
\text { hand-offs, or same-day } \\
\text { scheduling. }\end{array}$ \\
\hline & $\begin{array}{l}\text { Contributes to education programs } \\
\text { to increase PCP capacity. }\end{array}$ & & \\
\hline
\end{tabular}

Source: Authors' analysis. 
primary care providers to access psychiatry notes. In traditional electronic medical records, accessing these types of notes is challenging because of state regulations. However, allowing access to this information greatly assists providers in remaining informed about patient care. Providers also share secure email and scheduling systems. Together, these systems are critical in facilitating frequent communication between providers.

In addition to making consultation easier between providers, the psychiatrists at the ACO have contributed to programming targeted at increasing primary care providers' capacity to treat behavioral health issues. The psychiatrists helped to create treatment guidelines for depression and anxiety for primary care providers. Also, they participate in the ACO's educational training programs for primary care doctors. For example, the psychiatrists might provide a presentation to primary care providers on the clinical use of psychotropic medications. These presentations and guidelines aim to increase primary care provider's comfort in managing patients with more complex behavioral health needs.

\section{Challenges and Benefits}

The limited availability of behavioral health providers has been a major implementation obstacle. The ACO was able to hire only two behavioral health providers because of shortages in the region. In addition, the overwhelming popularity of the psychiatric services has resulted in limited flexibility and availability of these providers. Because behavioral health providers typically provide hour-long sessions back-to-back, it is difficult to accommodate warm hand-offs and same-day scheduling. To overcome this staffing issue, the ACO plans to recruit social workers to expand its behavioral health capacity.

Despite challenges, the ACO has identified early benefits. One central advantage is the ability to manage patient care more effectively. For example, the ACO has worked with the behavioral health providers to ensure that the practice provides evidenced-based behavioral health care and has mechanisms to track patient outcomes. Additionally, the increased communication and visibility of psychiatric records has contributed to better continuity of care and fewer duplicated services. Finally, the ACO has benefitted from having local behavioral health expertise to improve primary care education programs. Overall, as this model grows and matures, it has the potential to improve care for patients and is a large step toward more fully integrated care.

\section{Considerations for Other Organizations}

Crystal Run Healthcare's model may be a good fit for organizations focused on treating either individuals with low-to-moderate physical and behavioral health needs or individuals with high physical health needs and low-to-moderate behavioral health needs. ${ }^{14}$ This model also may offer organizations new to providing behavioral health care or inexperienced with integration models an opportunity to begin coordinating and connecting behavioral and physical health care.

\section{Essentia Health ACO}

Essentia Health ACO has clinics operating across four Midwestern states: Wisconsin, Minnesota, North Dakota, and Idaho. The ACO is composed of an integrated delivery system with 18 hospitals, 63 clinics, and 1,500 providers. It has a number of ACO contracts, including private payer ACO contracts, a Medicare Shared Savings Program contract that began in July 2012, and a contract with Minnesota's Medicaid program that began in January 2013. In total, the ACO has 140,000 patients under ACO contracts. Essentia Health decided to comprehensively pursue behavioral health and primary care integration because of its participation in ACO contracts. While the organization attempted to provide limited integrated care in the past, modified reimbursement under $\mathrm{ACO}$ contracts has made an integrated care model financially viable. The ACO hopes investing in integrated care will improve the overall health of individuals-both physical and behavioral - and result in the reduction of unnecessary medical utilization.

\section{Integration Approach}

Essentia Health developed an integrated model that embeds behavioral health specialists within primary 
care teams, colocates providers, and establishes structures for frequent communication and close collaboration in patient care. The goal of the model-often called a primary care behavioral health model-is to build the capacity of PCPs to treat behavioral health patients and reduce the need for referrals to behavioral health specialists. Two key elements differentiate this model from other approaches: 1) the behavioral health providers support PCPs in managing patients' behavioral health needs, rather than directly managing patients' care and 2) care is delivered in primary care settings and is short-term, solution-focused, and skillbased rather than traditional long-term treatment or specialized interventions. ${ }^{15}$

Essentia Health's integrated primary care team currently includes three types of behavioral health providers with distinct roles: psychiatric nurse practitioners, behavioral health specialists (i.e., master degree-level clinicians), and consulting psychiatrists (Exhibit 4). ${ }^{16}$ While the roles of providers are varied, generally the

EXHIBIT 4. ROLES AND RESPONSIBILITIES OF ESSENTIA HEALTH ACO BEHAVIORAL HEALTH PROVIDERS

\begin{tabular}{|c|c|c|c|}
\hline $\begin{array}{l}\text { Provider title } \\
\text { (location, full-time/ } \\
\text { part-time) }\end{array}$ & Responsibilities & Direct Patient Care Role & Availability to PCPs \\
\hline \multirow[t]{2}{*}{$\begin{array}{l}\text { Behavioral health } \\
\text { specialist } \\
\text { (on-site, part- } \\
\text { or full-time) }\end{array}$} & $\begin{array}{l}\text { Assists with behavioral health } \\
\text { screenings. Provides a limited } \\
\text { number (approximately three to } \\
\text { eight) of short (15-to-30-minute) } \\
\text { therapy sessions focused on psycho- } \\
\text { education, motivational interviewing, } \\
\text { and basic or preventive behavioral } \\
\text { therapy skills. }\end{array}$ & $\begin{array}{l}\text { Short-term-Contingent on } \\
\text { referral from PCP and patient } \\
\text { need. }\end{array}$ & $\begin{array}{l}\text { High-Have blocks } \\
\text { of unscheduled time } \\
\text { available for questions, } \\
\text { crisis stabilization, warm } \\
\text { hand-offs, or same-day } \\
\text { appointments. }\end{array}$ \\
\hline & $\begin{array}{l}\text { Available for crisis stabilization, } \\
\text { intervention, or evaluation as } \\
\text { needed. }\end{array}$ & & \\
\hline $\begin{array}{l}\text { Consulting psychiatrist } \\
\text { (off-site, part-time) }\end{array}$ & $\begin{array}{l}\text { Consults with PCP and integrated } \\
\text { team on complex cases and assists } \\
\text { with diagnoses, treatment planning, } \\
\text { or medication management. }\end{array}$ & & \\
\hline
\end{tabular}

Note: Essentia Health also envisions adding behavioral health care coordinators to the primary care team to link patients to community resources and provide care coordination. However, at the time of the interviews, this role had not yet been filled.

Source: Authors' analysis. 
psychiatric nurse practitioner assists the PCP with diagnoses, treatment planning, and medication management; the behavioral health specialist assists the PCP with screenings and provides short-term, solutionfocused therapy to patients; and the psychiatrist consults with the PCP and other behavioral health providers on complex cases. Notably, under this model, behavioral health providers support primary care providers, and it is the PCP who retains supervision of patients' psychiatric care. This supervision includes managing and prescribing medications and making final diagnoses. Additionally, the PCP is responsible for making appropriate referrals to integrated behavioral health. For example, the PCP may refer a patient to the behavioral health specialist for short-term therapy or psychoeducation. Alternatively, PCPs may provide a referral to the psychiatric nurse practitioner for a formal in-person patient evaluation.

Essentia Health's model improves the availability and accessibility of behavioral health providers in two ways. First, behavioral health and physical health providers are colocated to facilitate interaction. Whenever possible, the psychiatric nurse practitioner and behavioral health specialists' offices are adjacent to the primary care provider's office. This physical proximity can remind busy PCPs of the availability of behavioral health resources. Second, availability and accessibility are improved through built-in, unscheduled blocks of time for behavioral health providers. Generally, behavioral health providers have at least half of their time unscheduled. For example, the behavioral health specialists have 30 minute blocks of time alternating between unscheduled and providing services. This unscheduled time can be used in a variety of ways-for example, for a PCP to introduce a patient with behavioral health needs to a specialist. This can help demystify psychiatric care and increase likelihood of follow-through on making a subsequent appointment with the specialist. Or, the psychiatric nurse practitioner might spend this time walking through the office to do informal consultations with PCPs regarding medication regimens.
In the past, Essentia Health had unsuccessfully attempted to implement a similar type of model and learned that adequate buy-in and support of primary care providers was essential. In the current model, responsibilities of behavioral health providers are tailored depending on the needs of primary care clinics. For example, while most clinics' nurse practitioners focus on mild-to-moderate-need patients, one clinic identified a lack of behavioral health specialists in the local area as a problem and thus chose to allocate some of their psychiatric nurse practitioner's time to review and assess patients with more complex needs. Because primary care providers have the ability to adapt the responsibilities of behavioral health providers, ownership and buy-in for the model have increased.

\section{Challenges and Benefits}

Three distinct challenges have emerged. First, participation in both ACO and fee-for-service financing environments has made it difficult to fully staff the integrated model. Specifically, the ACO has not yet hired any behavioral health care coordinators because ACO contract revenue cannot yet fully support these new positions and fee-for-service contracts do not cover the services that would be provided by the care coordinators. Second, getting buy-in for the cultural shift required has been a significant undertaking. To address this issue, the ACO focused on educating primary care leaders and has implemented the integrated program in sites with leadership committed to changing care delivery. Finally, geography has been a barrier, as the ACO has clinics in four states. The model has not yet been launched at all clinics because of varying state restrictions around the use of psychotherapy notes.

Despite these challenges, the model has already had a positive impact. Anecdotal reports from providers and patients indicate that patient care and access to services has improved. Essentia Health is developing surveys on patient and provider experience to further assess the program's efficacy. 


\section{Considerations for Other Organizations}

Essentia Health's model may work well for organizations that want to provide behavioral health care in a primary care setting. This model is well-suited for individuals with low-to-moderate behavioral health needs and low-to-high physical health needs. ${ }^{17}$ It is also a good fit for organizations with significant experience providing behavioral health services or with previous integration experience. Additionally, organizations that pursue this model will want to ensure that their organizational culture is prepared for and accepting of this type of radical shift in care delivery. This advanced integration model requires significant cultural change and shifts, but has the potential to truly reform the behavioral health care system.

\section{CONCLUSION}

The examples of Crystal Run Healthcare ACO and Essentia Health ACO show how participation in an ACO can support the use of integrated behavioral health and primary care models. In both cases, the organization's participation in an ACO enabled an integrated behavioral health and primary care model. For Crystal Run Healthcare, participation in an ACO contract led providers to integrate behavioral health because of new accountability for their quality of care. Essentia Health's participation in ACO contracts was similarly influential in their decision to integrate behavioral health into primary care clinics. Specifically, the flexibility in the payment structures allowed this ACO to make an integrated care model financially viable, which had been a barrier to implementation in the past. These results are consistent with the commentators that suggest ACOs are well-suited to pursue these models of care. ${ }^{18}$ Other organizations pursuing integrated behavioral health care should consider whether their payment and incentive structures will support care delivery transformation.

While appropriate payment models and cultural shifts are needed to successfully pursue integrated care, implementation also requires selecting a suitable integration model. Organizations should select a model based on characteristics like the patient population they are targeting, staffing capacity, organizational culture, and infrastructure capabilities. ${ }^{19}$ At Crystal Run Healthcare, for example, a colocation plus collaboration model was a sensible approach for a number of reasons. First, the ACO was not targeting a specific behavioral health diagnosis, thus it was important to have behavioral health providers that could provide an array of psychiatric care. Second, because Crystal Run Healthcare did not have internal behavioral health providers, the organization lacked staffing capacity to quickly create a fully integrated team with several types of behavioral health providers. Additionally, the colocation plus collaboration model is a prudent first step toward integration for an organization that has just begun offering behavioral health services because it requires only a moderate cultural shift as the primary care and behavioral health providers remain in their traditional roles. Finally, the ACO's preexisting infrastructure, which included electronic medical records, primary care education programs, and team meeting, further allowed for the successful implementation of the model.

For Essentia Health ACO, a fully integrated primary care behavioral health model was a good fit for several reasons. First, the ACO is focused on providing basic behavioral health care to a broad patient population. Second, the ACO has a robust network of behavioral health providers and expertise. Third, as with Crystal Run Healthcare, Essentia Health also had the required infrastructure to move toward integrated care. Finally, Essentia Health worked with PCPs to build a consensus around the cultural shift needed to implement this model, and opted to implement it at sites that had a leader who supports the mission and models cultural change. The decision to pursue a fully integrated model of care carefully considered the ACO's capabilities and organizational commitment to reducing fragmentation between physical and behavioral health care.

The transition to more integrated behavioral health and primary care in ACOs could be facilitated and supported by payers, states, or learning collaboratives. These partners are ideally situated to provide educational opportunities to ACOs considering or pursuing integrated care. For example, partners might provide 
training around improving communication between behavioral health and primary care providers to help reduce cultural barriers and relieve "siloed" working conditions. In addition, partners could convene venues to foster mentoring relationships between $\mathrm{ACO}$ sho have implemented a model of integration and those that have not yet begun design or implementation.

While the models we have described are compelling and promising, more data are needed to evaluate the effectiveness of integrated care for patient outcomes and the factors that lead to long-term, successful integration. In addition, while participating in an ACO may enable the use of integrated care models, ACOs should carefully consider the specific capacities and strengths of their organizations when selecting a model. Additional research should be conducted to help ACOs identify and select appropriate models for their unique characteristics. Ultimately, repairing our behavioral health system will require these innovative models that better connect primary care and behavioral health care providers. The success and spread of integration will rely on those ACOs at the forefront of care delivery transformation to adopt, test, and refine these models of care.

\section{APPENDIX. BEHAVIORAL HEALTH AND PRIMARY CARE INTEGRATION SPECTRUM}

\begin{tabular}{|c|c|c|c|c|c|}
\hline & Minimal & $\begin{array}{l}\text { Basic: at a } \\
\text { distance }\end{array}$ & Basic: on site & $\begin{array}{l}\text { Close: partly } \\
\text { integrated }\end{array}$ & $\begin{array}{l}\text { Close: fully } \\
\text { integrated }\end{array}$ \\
\hline Care facilities & Separate & Separate & Shared & Shared & Shared \\
\hline Systems & Separate & Separate & Separate & $\begin{array}{l}\text { Some separate, } \\
\text { some shared }\end{array}$ & Shared \\
\hline Communication & Sporadic if any & $\begin{array}{l}\text { Periodic, about } \\
\text { specific shared } \\
\text { patients }\end{array}$ & $\begin{array}{l}\text { Periodic, in general } \\
\text { and about specific } \\
\text { shared patients }\end{array}$ & $\begin{array}{l}\text { Frequent face-to- } \\
\text { face, in general } \\
\text { and about specific } \\
\text { shared patients }\end{array}$ & $\begin{array}{l}\text { Frequent face-to- } \\
\text { face, in general } \\
\text { and about specific } \\
\text { shared patients }\end{array}$ \\
\hline $\begin{array}{l}\text { Team/Work } \\
\text { Atmosphere }\end{array}$ & $\begin{array}{l}\text { Professional } \\
\text { domains separate }\end{array}$ & $\begin{array}{l}\text { Professional } \\
\text { domains separate }\end{array}$ & $\begin{array}{l}\text { Professional } \\
\text { domains separate }\end{array}$ & $\begin{array}{l}\text { Sense of being } \\
\text { part of a larger } \\
\text { team with separate } \\
\text { professional roles }\end{array}$ & $\begin{array}{l}\text { Behavioral health } \\
\text { and primary care } \\
\text { providers are part of } \\
\text { the same treatment } \\
\text { team }\end{array}$ \\
\hline
\end{tabular}




\section{NOTES}

1 D. R. Jones, C. Macias, P. J. Barreira et al., "Prevalence, Severity, and Co-occurrence of Chronic Physical Health Problems of Persons With Serious Mental Illness," Psychiatric Services, Nov. 2004 55(11):1250-57; C. W. Colton and R. W. Manderscheid, "Congruencies in Increased Mortality Rates, Years of Potential Life Lost, and Causes of Death Among Public Mental Health Clients in Eight States," Preventing Chronic Disease Public Health Research, Practice and Policy, March 2006 3(2):1-14; R. C. Kessler, O. Demler, R. G. Frank et al., “U.S. Prevalence and Treatment of Mental Disorders, 1990 to 2003," New England Jounral of Medicine, June 16, 2005 352(24):2515-23; and J. Sareen, A. Jagdeo, B. J. Cox et al., "Perceived Barriers to Mental Health Service Utilization in the United States, Ontario, and the Netherlands," Psychiatric Services, March 2007 58(3) 357-64.

2 B. Richman, D. Grossman, and F. Sloan, "Fragmentation in Mental Health Benefits and Services: A Preliminary Examination into Consumption and Outcomes," in The Fragmentation of U.S. Health Care: Causes and Solutions (Einer Elhauge ed., 2010); and M. Horvitz-Lennon, A. M. Kilbourne, and H. A. Pincus, "From Silos to Bridges: Meeting the General Health Care Needs of Adults with Severe Mental Illnesses," Health Affairs, May/June 2006 25(3):659-69.

3 M. Butler, R. L. Kane, D. McAlpine et al., Integration of Mental Health/Substance Abuse and Primary Care (Rockville, Md.: Agency for Healthcare Research and Quality, 2008); and E. Woltmann, A. Grogan-Kaylor, B. Perron et al., "Comparative Effectiveness of Collaborative Chronic Care Models for Mental Health Conditions Across Primary, Specialty, and Behavioral Health Care Settings: Systematic Review and Meta-Analysis," American Journal of Psychiatry, Aug. 2012 169(8):790-804.

4 B. Heath, P. Romero Wise, and K. Reynolds, A Standard Framework for Levels of Integrated Healthcare (Washington, D.C.: Substance Abuse and Mental Health Services Administration, 2013); and C. Collins, D. L. Hewson, R. Munger et al., Evolving Models of Behavioral Health Integration in Primary Care (New York: Milbank Memorial Fund, 2010).

5 A. N. O'Donnell, M. Williams, and A. M. Kilbourne, “Overcoming Roadblocks: Current and Emerging Reimbursement Strategies for Integrated Mental Health Services in Primary Care," Journal of Internal Medicine, Dec. 2013 28(12):1667-72.

6 A. Auxier, C. Runyan, D. Mullin et al., "Behavioral Health Referrals and Treatment Initiation Rates in Integrated Primary Care: A Collaborative Care Research Network Study," Translational Behavioral Medicine, Sept. 1, 2012 2(3):3337-44; and B. F. Miller, S. Petterson, B. T. Burke et al., "Proximity of Providers: Colocating Behavioral Health and Primary Care and the Prospects for an Integrated Workforce," American Psychologist, May-June 2014 69(4):443-51.

7 D. T. Maust, D. W. Oslin, and S. C. Marcus, "Mental Health Care in the Accountable Care Organization," Psychiatric Services, Sept. 2013 64(9):908-10; and A. N. O'Donnell, B. C. Williams, D. Eisenberg et al., "Mental Health in ACOs: Missed Opportunities and Low Hanging Fruit," American Journal of Managed Care, March 2013 19(3):180-84.

8 While many ACOs are accountable for the total cost of care, including behavioral health costs, there are few quality metrics specifically focused on behavioral health treatment. Each individual ACO decides if or how it will hold individual providers responsible for this component of cost of care.

9 E. S. Fisher, S. M. Shortell, S. A. Kreindler et al., "A Framework for Evaluating the Formation, Implementation, and Performance of Accountable Care Organizations," Health Affairs, Nov. 2012 31(11):2368-78; and M. McClellan, A. N. McKethan, J. L. Lewis et al., "A National Strategy to Put Accountable Care into Practice," Health Affairs, May 2010 29(5):982-90.

10 C. H. Colla, D. E. Wennberg, E. Meara et al., "Spending Differences Associated with the Medicare Physician Group Practice Demonstration," Journal of the American Medical Association, Sept. 2012 308(10):1015-23; and O'Donnell, Williams, Eisenberg et al., "Mental Health in ACOs," 2013.

1 V. A. Lewis, B. Kennedy Larson, A. B. McClurg et al., "The Promise and Peril of Accountable Care for Vulnerable Populations: A Framework for Overcoming Obstacles," Health Affairs, Aug. 2012 31(8):1777-85; and Colla, Wennberg, Meara et al., "Spending Differences," 2012.

12 V. A. Lewis, C. H. Colla, K. Tierney et al., "Few ACOs Pursue Innovative Models That Integrate Care for Mental Illness and Substance Abuse with Primary Care," Health Affairs, Oct. 2014 33(10):1808-16. 
13 The social workers will be responsible for providing evidenced-based psychotherapy to patients under the supervision of the psychiatrists.

14 Collins, Hewson, Munger et al., Evolving Models, 2010.

15 Ibid.

16 Essentia Health ACO also envisions adding behavioral health care coordinators to the primary care team to link patients to community resources and to add care coordination services. At the time of our interviews, this role had not yet been filled.

17 National Council for Community Behavioral Healthcare, "National Council's Revised Four Quadrant Model," National Council Magazine, 2009:10-11.

18 O’Donnell, Williams, Eisenberg et al., “Mental Health in ACOs,” 2013.

19 Collins, Hewson, Munger et al., Evolving Models, 2010. 
- 0 The COMMONWEALTH FUND 